\title{
Genome-wide association studies in economics and entrepreneurship research: promises and limitations
}

\author{
Philipp D. Koellinger • Matthijs J. H. M. van der Loos • \\ Patrick J. F. Groenen • A. Roy Thurik • Fernando Rivadeneira • \\ Frank J. A. van Rooij · André G. Uitterlinden · Albert Hofman
}

Accepted: 20 April 2010/Published online: 13 May 2010

(C) The Author(s) 2010. This article is published with open access at Springerlink.com

\begin{abstract}
The recently developed genome-wide association study (GWAS) design enables the identification of genes specifically associated with economic outcomes such as occupational and other choices. This is a promising new approach for economics research which we aim to apply to the choice for entrepreneurship. However, due to multiple testing issues, very large sample sizes are needed to differentiate between true and false positives. For a GWAS on entrepreneurship, we expect that a sample size of at least 30,000 observations is required.
\end{abstract}

P. D. Koellinger $(\varangle) \cdot$ M. J. H. M. van der Loos •

A. R. Thurik

Department of Applied Economics, Erasmus School of Economics, Erasmus University Rotterdam, P.O. Box 1738, 3000 DR Rotterdam, The Netherlands e-mail: koellinger@ese.eur.nl

M. J. H. M. van der Loos

e-mail: mvanderloos@ese.eur.nl

\section{A. R. Thurik \\ e-mail: thurik@ese.eur.nl \\ P. J. F. Groenen}

Econometric Institute, Erasmus School of Economics, Erasmus University Rotterdam, P.O. Box 1738,

3000 DR Rotterdam, The Netherlands

e-mail: groenen@ese.eur.nl

F. Rivadeneira · F. J. A. van Rooij ·

A. G. Uitterlinden · A. Hofman

Department of Epidemiology, Erasmus Medical Center, P.O. Box 2040, 3000 CA Rotterdam, The Netherlands e-mail: f.rivadeneira@erasmusmc.nl
Keywords Genetics · Microeconomics · Entrepreneurship

JEL Classifications $\quad$ L26 $\cdot$ J24 $\cdot$ B40 $\cdot$ C10

\section{Introduction}

There are two popular views on what makes an entrepreneur. The first is that anyone can learn the necessary skills provided (s)he puts in enough time

F. J. A. van Rooij

e-mail: f.vanrooij@erasmusmc.nl

A. G. Uitterlinden

e-mail: a.g.uitterlinden@erasmusmc.nl

A. Hofman

e-mail: a.hofman@erasmusmc.nl

F. Rivadeneira - A. G. Uitterlinden

Department of Internal Medicine, Erasmus Medical

Center, P.O. Box 2040, 3000 CA Rotterdam,

The Netherlands 
and effort. The second is that people are either born with the right personality and skills or they are not, and there is not much that one can do about it. Obviously, which of these two stories is true has farreaching implications for individual behavior and economic policies. As we discuss below, there is increasing evidence that inherited qualities play a role in occupational choice with recent scientific advances showing different pathways through which genes can influence entrepreneurial behavior. However, in contrast to popular views, a genetic influence does not imply any kind of determinism, irrelevance of the environment, or of free will, as we discuss later.

The recent scientific breakthroughs that make it possible to discover the genetic basis of human behavior and traits are linked to the results of the Human Genome (Collins et al. 2003) and HapMap projects (The International HapMap Consortium 2005). These projects decoded the human genome and identified those genetic regions where humans frequently exhibit differences, which is only a very small part of the entire genome. This resulted in new technological developments that allow the genotyping $^{1}$ of hundreds of thousands of markers in large samples at reasonable costs. In particular, a new generation of studies of variations across the entire human genome, called genome-wide association studies (GWAS), have launched an unprecedented era of genetic discoveries, already resulting in more than 500 published studies, identifying common variants associated with numerous complex quantitative traits and diseases (Hindorff et al. 2009). GWASs focus on so-called single nucleotide polymorphisms (SNPs, pronounced 'snips'), base pairs that differ between members of a species, which cover a high proportion of the common genetic variation within the genome. This study design provides insights into biological processes and improves our understanding of the biological origins of differences among human beings. This is an important step toward putting the old debate about whether entrepreneurs are born or made through a rigorous scientific test focusing on the genes. Furthermore, this study design is also

\footnotetext{
$\overline{1}$ Genotyping refers to determining the genotype of an individual by the use of biological assays which are also called DNA microarrays. These microarrays integrate several laboratory functions on a single chip that is suitable for highthroughput screening methods.
}

applicable to various other outcomes of economic relevance, such as educational attainment, risk preferences, and income.

From an economics perspective, the idea that genes influence behavior seems far-fetched at first glance. Typically economists focus on understanding the role of the environment in shaping human behavior, the interactions of people, and the consequences of these interactions. Economists sometimes find it convenient to study the behavior of 'representative agents' (Kirman 1992; Hartley 1996). However, there is ample scope for individuality in economic models, which is typically formalized in the form of preferences ${ }^{2}$ or productivity values ${ }^{3}$ that depend on personal characteristics. Such individual differences are likely to have important economic implications. For example, we know that occupational choice depends on risk and uncertainty preferences (Knight 1921; Kihlstrom and Laffont 1979; Iyigun and Owen 1998), as well as on non-monetary preference for independence (Benz and Frey 2008; Block and Koellinger 2009), educational attainment (Evans and Leighton 1989), skills (Jovanovic 1994; Lazear 2004, 2005; Laussel and Le Breton 1995; Roessler and Koellinger 2009), gender (Grilo and Thurik 2008) and a tendency to be overconfident and overly optimistic (Camerer and Lovallo 1999; Koellinger et al. 2007). All these individual attributes are candidates for an indirect genetic influence on occupational choice. ${ }^{4}$

In fact, there is growing empirical evidence from studies of twins that individual characteristics, which can affect the tendency to become an entrepreneur, are indeed at least partially due to genetic differences. Examples include preferences for risk seeking (Cesarini et al. 2009a), altruism in dictator games (Knafo et al. 2008; Israel et al. 2008), job satisfaction

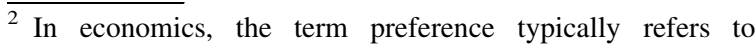
theoretical assumptions about the rank order between different choices according to the degree of desirability to an individual.

${ }^{3}$ For example, the labor productivity of a person measures output per labor-hour, given a particular production technology and capital input. Differences in labor productivity are often attributed to personal characteristics such as education or experience.

${ }^{4}$ Other attributes of an environmental nature such as (the threat of) unemployment (Thurik et al. 2008) and the institutional environment (Freytag and Thurik 2007) may play moderating roles.
} 
(Arvey et al. 1989), vocational interests (Betsworth et al. 1994), work values (Keller et al. 1992), novelty seeking (Ebstein et al. 1996; Kluger et al. 2002), gambling (Pérez de Castro et al. 1997; Comings et al. 1996), general cognitive ability and intelligence (Deary et al. 2006; Plomin 1999; Plomin and Kosslyn 2001; Plomin and Spinath 2004), educational attainment (Miller et al. 2001), and overconfidence (Cesarini et al. 2009b).

In addition, empirical evidence suggests that entrepreneurship tends to run in families. Lentz and Laband (1990) observe that around half of all US selfemployed proprietors are second-generation business owners. Evans and Leighton (1989) find that the likelihood of self-employment increases if the father is a manager, and decreases if the father is unskilled. Furthermore, Dunn and Holtz-Eakin (2000) find that parental self-employment both increases the fraction of time that offspring spend in self-employment and reduces the age at which they enter. Colombier and Masclet (2008) find intergenerational correlation for self-employment in France. Andersson and Hammarstedt (2010) show that having both a self-employed father and a self-employed grandfather positively effects self-employment propensities for third-generation male immigrants in Sweden. Finally, Van der Zwan et al. (2010) show that people with selfemployed parents climb the 'entrepreneurial ladder' more quickly than those without such parents. It seems likely that self-employed parents transfer relevant skills and familiarity with entrepreneurial behavior to children. But it could also be that inherited characteristics explain the observed intergenerational effects. Indeed, several comparative twin studies suggest a potential genetic influence on the propensity to become self-employed (Nicolaou et al. 2008a, b; Nicolaou and Shane 2009; Zhang et al. 2009).

In late 2007, these thoughts and findings encouraged us to start investigating the human genome to identify genetic causes of entrepreneurial behavior using GWAS. We assembled a multidisciplinary research group of economists and genetic epidemiologists, establishing the Gentrepreneur Consortium (Van der Loos et al. 2010). To the best of our knowledge, this is the earliest attempt to apply GWAS to an economic outcome of a relatively general, and hence complex, nature. We are aware that the entrepreneurial choice is possibly a very complex one to explain because entrepreneurship is a multidimensional phenomenon about which there is no general agreement. Not only have psychology, economics, anthropology, and business studies widely different views but also the more popular view of what entrepreneurship is, seems to vary with time and space (Bygrave and Hofer 1991; Wennekers and Thurik 1999; Verheul et al. 2005). In the present study we measure entrepreneurial activity with selfemployment which is an established and widely used measure.

Our GWAS uses data from the Rotterdam Study (Hofman et al. 2009). The Rotterdam Study is a prospective cohort study, hosted at the Erasmus University Rotterdam Medical Center. The majority of the genotyped individuals in the Rotterdam Study provided data on their occupational status, allowing us to study entrepreneurial behavior by looking at selfemployment. The present article is inspired by our ongoing work with this data and employs simulations to illustrate important identification issues in GWAS in general. Our simulations mimic several characteristics of the Rotterdam Study, such as sample size $(N \sim 10,000)$, the prevalence of self-employment ( $\sim 10 \%$ of the sample) and the number of SNPs ( 550,000).

We presented preliminary results using RS-I at the Behavior Genetics Association June 2008 conference in Louisville, Kentucky (Groenen et al. 2008). Since then our work has focused on replicating results using independent samples and we have now embedded our effort to assemble a working group (Gentrepreneur) within the Cohorts for Heart and Aging Research in Genomic Epidemiology (CHARGE) consortium (Psaty et al. 2009). As we discuss below, replication is crucial for this type of research and our efforts to replicate the findings from our discovery cohort are ongoing.

In this article, we describe the GWAS design and how it can be applied to study economic outcomes. We illustrate the statistical multiple testing problem that arises in this context when using simulation studies that closely mimic a GWAS setting on entrepreneurship. Following current best practice in genetics research, we discuss how strict confidence levels in combination with large sample sizes are required to identify genes that are truly associated with entrepreneurship or other economic outcomes. Furthermore, the interpretation of findings from GWAS on economic outcomes is not straightforward 
and this article provides several guidelines in this regard.

We begin by describing some basic genetic concepts and the principles underlying genome-wide association studies (GWAS) in Sect. 2. From the setup of GWAS, the multiple testing problem arises, which we describe in detail and illustrate with a series of simulations in Sect. 3. The interpretation of results from GWAS is discussed in Sect. 4. Section 5 concludes and outlines some possible future potential of GWAS for economics and entrepreneurship research.

\section{Basic genetic concepts and genome-wide association studies}

The human genome comprises all genetic information in human cells and consists of 23 chromosomal pairs (46 in total); half is inherited from the mother and half from the father. These chromosomes 'package' DNA molecules encode the genetic information in a linear sequence of chemical bases along two DNA strands. A DNA strand is a polymer of nucleotides. Each nucleotide is a building block consisting out of a phosphate, a sugar, and a base. The base in a nucleotide can be Adenine (A), Cytosine (C), Guanine (G), or Thymine (T); thus there are four distinct nucleotides. DNA is structured as a double helix in which two DNA strands are held together by weak hydrogen bonds to form a DNA duplex. Hydrogen bonding occurs between the bases of opposing nucleotides along the two strands: Adenine always binds to Thymine and Cytosine always binds to Guanine. Consequently, two DNA strands of a DNA duplex are said to have complementary sequences and the sequence of one DNA strand can easily be inferred if the DNA sequence of its complementary strand is already known. It is usual, therefore, to describe a DNA sequence by writing the sequence of bases for only one strand. For example, one individual may have inherited the AA nucleotides for one particular position on a pair of chromosomes (i.e. a genotype). This would imply the individual inherited an A base from the paternal chromosome and an A base from the maternal chromosome. Another individual may have inherited AG nucleotides at the same position, a different base from each of the two parents, while a third may have inherited both GG nucleotides from each parent.
Alternative bases in a nucleotide at the same physical locus are called alleles. A DNA sequence on one position of the genome that exhibits at least $1 \%$ variation between members of a species is called a Single Nucleotide Polymorphism (SNP). The minor allele frequency (MAF) refers to the frequency of the less common allele of a SNP in a population. People having two copies of the same allele are said to be homozygous for this allele. On the other hand, individuals having two different alleles are called heterozygous.

Almost all human DNA-99.9\% of the three billion nucleotides that make up the human genome-is identical from person to person. The remaining $0.1 \%$ of the genome varies by SNPs (and other types of genomic variation), which is what makes humans different from each other. The total number and locations of SNP markers that need to be genotyped in order to detect an association between common genetic variants and an outcome of interest (also know as the 'phenotype' of an individual) was identified by the HapMap project (The International HapMap Consortium 2005). Facilitated by the results of the HapMap project, high throughput array-based technologies for whole-genome SNP analysis were recently developed.

GWAS is facilitated by a phenomenon called linkage disequilibrium (LD). LD refers to the nonrandom way SNPs are inherited together, i.e. many SNPs on the human genome are systematically correlated. SNPs in perfect linkage disequilibrium are inherited together, while SNPs in perfect linkage equilibrium are inherited randomly. LD makes it possible to discover which SNP is causing an outcome even if the SNP is not genotyped. In this case SNPs that are genotyped and in LD with the causal SNP are associated with the outcome. Thus, when a significant association is found between a SNP and an outcome, the association is not necessarily causal. However, the known systematic correlations of SNPs may still enable researchers to identify the causal gene by looking up SNPs that are in LD to the candidate loci. ${ }^{5}$ LD patterns in the human genome have been charted by the HapMap project and are used to reduce the number of SNPs

\footnotetext{
5 In practice, the identification of the true causal gene is limited by the fact that the biological function of most SNPs is still not well understood.
} 
that need to be included in an assay to cover a broad spectrum of the genome.

Typically, genotyping is currently done with 550,000 SNP arrays that, after data cleaning, tend to deliver information about the specific alleles for around 500,000 SNPs that are available for statistical analysis. Although this already gives a high resolution image of the human genome, next generation microarrays will allow researchers to assay 2-12 million markers per sample, including comprehensive coverage of both common and rare variants.

The basic GWAS design is to associate an outcome of interest, such as the presence of a disease, an IQ score, or the employment status of an individual (called 'phenotype'), with SNPs on the chip, usually by carrying out a bivariate statistical test for each SNP. Hence, GWAS is an exploratory method that does not rely on prior hypotheses about expected relationships. For a binary outcome like entrepreneurship (with $y=1$ meaning the individual is an entrepreneur, and $y=0$ otherwise), the bivariate test performed for each SNP typically consists of a Pearson's chi-square test for independence within a two-by-two contingency table. The columns in this table indicate the status of the outcome, while the rows indicate one of two alleles for a certain SNP. The table is constructed by collapsing a three-by-two table into the two-by-two table. For example, Table 1 classifies individuals according to their genotype for a certain SNP, which is AA, AG, or GG, and according to their status of the outcome. The table shows there are $a$ subjects with $y=1$ with genotype AA for this $\mathrm{SNP}, b$ subjects with $y=0$ with genotype AA, and so on. This table can be collapsed into a two-by-two table by counting the number of alleles for each allele of this SNP (A and G). This results in Table 2, where the letters refer to the ones used in Table 1. This is done to increase the power of the test, as the test within the two-by-two table is a 1 degree of freedom test in contrast to the 2 degrees of freedom test within the

Table 1 Genotype counts in a study for a binary outcome and a particular SNP

\begin{tabular}{lll}
\hline Genotype & $y=1$ & $y=0$ \\
\hline AA & $a$ & $b$ \\
AG & $c$ & $d$ \\
GG & $e$ & $f$ \\
\hline
\end{tabular}

Table 2 Allele counts in a study for a binary outcome and a particular SNP

\begin{tabular}{lll}
\hline Allele & $y=1$ & $y=0$ \\
\hline $\mathrm{A}$ & $2 a+c$ & $2 b+d$ \\
$\mathrm{G}$ & $2 e+c$ & $2 f+d$ \\
\hline
\end{tabular}

three-by-two table. A chi-square test for independence is carried out for each SNP in the study based on tables like Table 2.

Alternatively, a logistic regression on the outcome of interest can be carried out for each SNP, and each regression equation may include additional control variables. If 500,000 SNPs are available for statistical analyses, this implies that 500,000 chi-square tests or 500,000 logistic regressions must be conducted. Typically, these analyses are carried out using specialized software such as PLINK (Purcell et al. 2007).

However, collapsing the two-by-three table into a two-by-two table can only be done under the assumption that the so-called Hardy-Weinberg Equilibrium (HWE) (Hardy 1908; Weinberg 1908) holds within the complete sample (Sasieni 1997; Guedj et al. 2008). HWE is a population genetics law stating that genotype and allele proportions are constant in a population from generation to generation, given that the population is large, mating is random, there are no mutations, and there is no selection or migration. Deviations from HWE may indicate one of the above-mentioned phenomena, but may also imply genotyping errors or population stratification. Therefore, it is imperative to test SNPs for HWE before running a GWAS.

Understanding HWE and how to test for it requires some knowledge of the mathematics of HWE. It is quite straightforward and as follows. Assume that the proportions of the alleles $A$ and $\mathrm{G}$ in a population are given by $p$ and $q$, respectively. Furthermore, assume that $p$ and $q$ are identical for females and males in a population, mating is random, and that the population is large. Under these assumptions, a so-called Punnett square can be constructed (see Table 3) to derive the possible genotypes in the next generation and their proportions. Table 3 shows that offspring in the next generation randomly receive either the $\mathrm{A}$ or the $\mathrm{G}$ allele from their mother and father. This results in the three possible genotypes: AA, AG, and GG. Furthermore, under the independence assumption the 
Table 3 Punnett square for the alleles A and G with proportions $p$ and $q$

\begin{tabular}{lll}
\hline Father allele & \multicolumn{2}{l}{ Mother allele } \\
\cline { 2 - 3 } & $\mathrm{A}(p)$ & $\mathrm{G}(q)$ \\
\hline $\mathrm{A}(p)$ & $\mathrm{AA}\left(p^{2}\right)$ & $\mathrm{AG}(p q)$ \\
$\mathrm{G}(q)$ & $\mathrm{AG}(p q)$ & $\mathrm{GG}\left(q^{2}\right)$ \\
\hline
\end{tabular}

Proportions are given in parentheses

expected proportions of the genotypes in the next generation are $p^{2}$ for A homozygotes, $2 p q$ for heterozygotes, and $q^{2}$ for $\mathrm{G}$ homozygotes. Finally, based on the above, and given that the allele and genotype proportions must sum to one, we can derive two equations: $p+q=1$ and $p^{2}+2 p q+q^{2}=1$.

There are three steps to perform the test of whether a specific SNP fulfills HWE: First, the proportion of the observed alleles in the population is calculated. Second, using the latter equation and the computed allele proportions, the expected genotype proportions can be obtained. Finally, the expected genotype proportions can be compared to the genotype proportions observed in the population using a simple one degree of freedom chi-square test (Crisp et al. 1978).

\section{Identification of true positives}

The very large numbers of independent statistical tests that must be carried out in this research design lead to a severe multiple testing problem. In other words, it is expected that just on the basis of pure chance a large number of SNPs will show highly significant associations even if there is no actual relationship between a SNPs and the studied outcome. For example, assume that none of the analyzed 500,000 SNPs are truly associated with the outcome, i.e. the statistical null hypothesis of no association between SNP and outcome is correct. If we adopt a $1 \%$ significance level for hypothesis testing, performing 500,000 tests will yield 5,000 expected incorrect rejections of the null hypothesis (i.e. false positives). Even an apparently stringent significance level of 0.00001 (equivalent to a $P$ value of $10^{-5}$ ) still leads to 5 false positives on average. Not surprisingly, many GWAS often yield SNPs with $P$ values in this range, even studies with relatively small samples. As a result, many early GWAS studies reported findings that could not be later replicated (Hirschhorn et al.
2002). Hence, to keep the false positive rate at an acceptably low level, stringent significance levels are now used in GWAS to compensate for multiple testing. The often-used Bonferroni correction, for example, suggests a significance level of $10^{-7}$ for individual tests in order to obtain a $5 \%$ significance level for the whole family of 500,000 tests. On the other hand, due to linkage disequilibrium one is essentially conducting more tests than the number of genotyped SNPs. The generally accepted opinion is to account for at least 1 million independent tests in a European descent GWAS (McCarthy et al. 2008; The International HapMap Consortium 2005; Hoggart et al. 2008). Based on this, the Bonferroni correction proposes a significance level of $5 \times 10^{-8}$ to obtain a family-wise significance level of $5 \%$. This level is often referred to as 'genome-wide significance' and only SNPs that pass this threshold are typically considered to be true positives. However, to reach such high levels of significance, very large sample sizes are needed to be able to discover associations with weak effects (McCarthy et al. 2008).

To demonstrate the need for large sample sizes in order to find small effects, we performed several simulation studies that mimic the situation of a GWAS on entrepreneurship. We simulated datasets of three different sizes $(n=1,000, n=10,000$, and $n=$ $30,000)$ with 550,000 SNPs for each observation. The SNPs are unlinked and in perfect linkage equilibrium for different sample sizes. Subsequently, a GWAS was performed on the simulated data sets. Simulation and association was performed using PLINK software (Purcell et al. 2007). For the simulation of SNPs a trait prevalence of $10 \%$ in the population was assumed, which is roughly comparable to the prevalence of entrepreneurship in both the Netherlands and in our discovery cohort, the Rotterdam Study. Therefore, to mimic the true setting as closely as possible, the ratio between non-entrepreneurs and entrepreneurs is also 9 to 1 in the simulated data sets. The allele frequencies range from 0 to 1 and the effect allele is assumed to act multiplicatively, i.e. the odds ratio for people having two copies of the effective allele is the square of the odds ratio associated with having just one copy of the effective allele. Note that this amounts to an additive effect on the log scale. ${ }^{6}$

\footnotetext{
${ }^{6}$ Details about how the simulated data was generated can be requested from the authors.
} 
Before the association analysis, SNPs that failed a test of Hardy-Weinberg equilibrium (HWE) at the $10^{-6}$ level in subjects with $y=0$ were dropped. In the data sets for $n=10,000$ and $n=30,000$ this resulted in 1 and 18 SNPs, respectively, being dropped. No SNPs were dropped due to HWE testing in the other data set. After that, alleles with a minor allele frequency (MAF) smaller than 5\% were also filtered out. For all three data sets approximately 55,000 SNPs failed the MAF filter and were dropped from the analysis. As said, testing for HWE in subjects with $y=0$ is necessary for the chi-square test within a two-by-two table to be valid. SNPs in the simulation study can be out of HWE because they are generated randomly not taking HWE into account, whereas in practice, in absence of true association, deviation from HWE proportions will very likely reflect genotyping errors.

Of the 550,000 SNPs, five sets of each thirty SNPs were simulated with a known association with the trait with odds ratios of 1.2, 1.5, 1.7, 2 and 3. The remaining SNPs (549,850 in total) were simulated with an odds ratio of exactly one and, consequently, are not associated with the trait. Finally, the analysis was performed using chi-square tests for independence in a two-by-two table for each SNP, as described above.

The results of the simulation studies are plotted below as density histograms of the $P$ values (Figs. 1, 2). The two figures are only different in the sample size used for the analysis, with 1,000 observations for Fig. 1 and 10,000 observations for Fig. 2. In these histograms the $y$-axis is the frequency density, which is the relative frequency divided by the bin width, which is 0.05 given that 20 bins of equal width are used on a scale from 0 to 1 (Sturges 1926). Note that the total area of all bins sums to one and the bin size multiplied by its density is the relative frequency of the observations falling in that bin. Furthermore, below the histograms the $P$ values of the associated SNPs are plotted using different symbols to indicate different odds ratios. The dotted line indicates the conventional significance level of 0.01 . Finally, the dashed line is the genome-wide significance level of $5 \times 10^{-8}$. Figures 1 and $2 \mathrm{a}$ show the entire range of $P$ values generated by the GWAS. As one can expect, the randomly generated SNPs result in an almost uniform distribution of $P$ values. Importantly, the true positives with an odds ratio of greater than one cannot be differentiated from the other SNPs when small samples, with $n=1,000$, are used, as shown in Fig. 1. Most true positives with odds ratios of smaller than 2 do not even reach the conventional significance level of 0.01. Apparently, this study is severely underpowered to detect true positives with low odds ratios.

In contrast, when using the larger sample size of $n=10,000$, clustering of true positives with an odds ratio of 1.5 and higher is exhibited around the dashed line at the right of panel (a) of Fig. 2, which indicates genome-wide significance. However, from this figure it is not clear how well the study differentiates between true and false positives at $P$ values smaller than 0.01 . One must zoom into this area to learn more about the power of GWAS at larger samples sizes. One way to zoom into the relevant area of low $P$ values in panel (a) of Fig. 2 is by transforming the $x$-axis to the $-\log _{10}(P$ value $)$. This is done in panel (b) of Fig. 2.
Fig. 1 Histogram of simulated $P$ values with $n_{y=1}=100$ and $n_{y=0}=900$. In total 550,000 SNPs are simulated, including 5 sets of 30 SNPs with odds ratios greater than 1, i.e. 150 SNPs have a known association with $y=1$. Frequency density is the relative frequency divided by the bin width so that the area of all bins sums to one

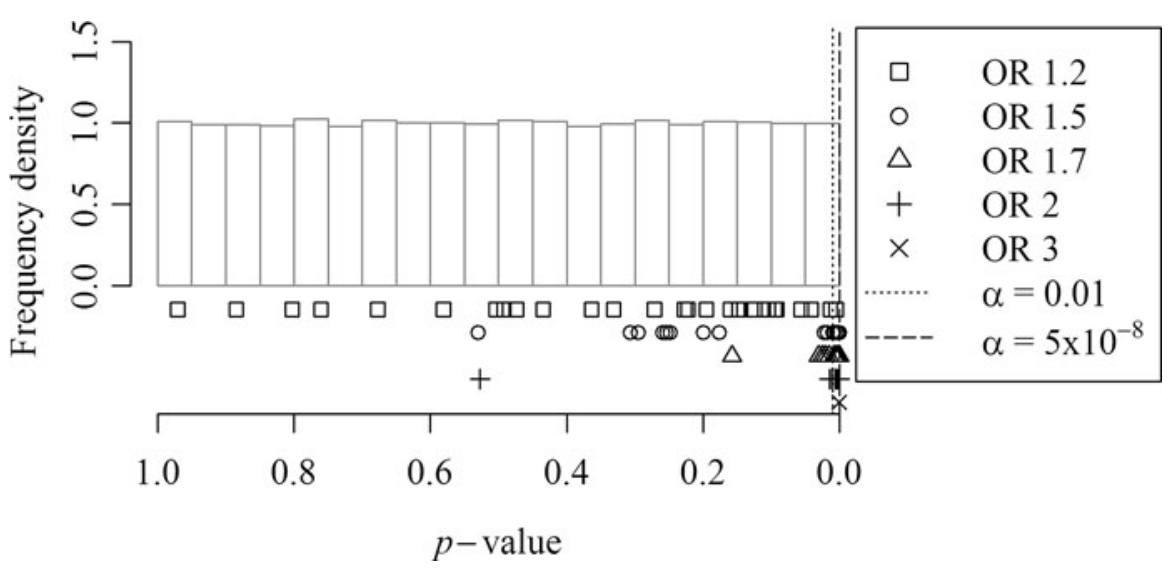


Fig. 2 Histograms of simulated $P$ values with $n_{y=1}=1,000$ and $n_{y=0}=9,000$. In total 550,000 SNPs are simulated, including 5 sets of 30 SNPs with odds ratios greater than 1, i.e. 150 SNPs have a known association with $y=1$. Frequency density is the relative frequency divided by the bin width so that the area of all bins sums to one. Panels $\mathbf{a}$ and $\mathbf{b}$ show the same data, except that in panel $\mathbf{b}$ the $x$ axis is transformed to the $-\log _{10}$ scale

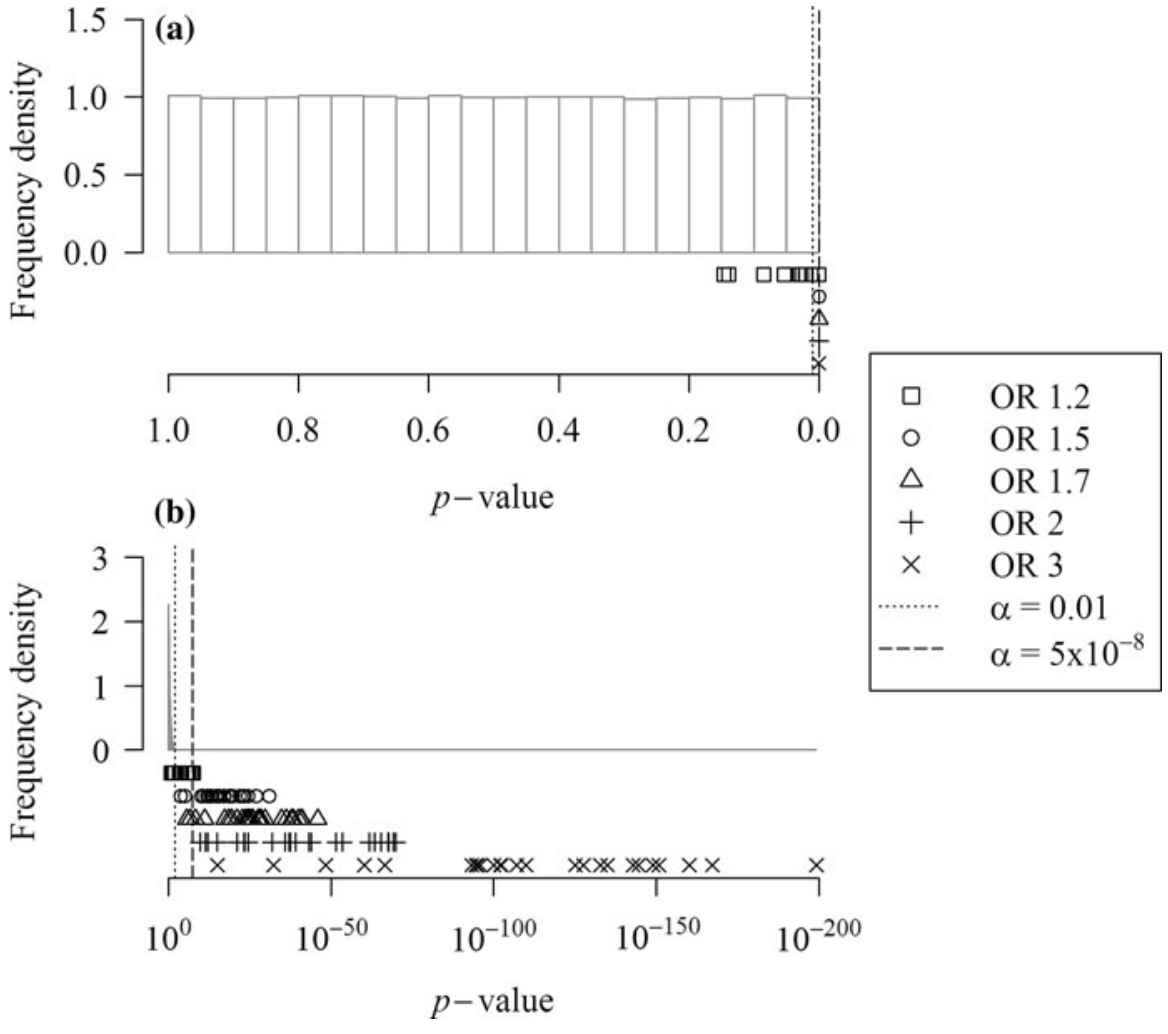

Another way to better visualize false and true positives is to plot the different odds ratios against the $P$ values using a $-\log _{10}$ scale on the $x$-axis (Fig. $3 a-c$ ). These plots make it possible to see how associated SNPs compare to un-associated SNPs at different sample sizes and odds ratios. Again, the conventional confidence level of 0.01 is indicated by a dotted line and genome-wide significance at $5 \times 10^{-8}$ with a dashed line.

Figure 3a plots the results of the GWAS with a sample size of $n=1,000$, similar to Fig. 1. Apparently it is impossible to differentiate between false positives and true positives with an odds ratio less than 3 with this sample size, while true positives with an odds ratio greater than or equal to 3 will probably be detected. In addition, most true positives with an odds ratio smaller than 1.7 do not even reach the conventional significance level of 0.01 and will remain undetected. A GWAS on entrepreneurship with a sample size of $n=1,000$ is severely underpowered to detect true positives with low odds ratios.

A tenfold increase in sample to $n=10,000$ resolves these problems for most SNPs with an odds ratio of 1.5 or higher, as shown in Fig. 3b. However, the low odds ratios of 1.2 still cannot be differentiated from false positives because they are unlikely to reach the threshold level of genome-wide significance. Furthermore, we see that the genome-wide significance threshold is rather conservative: No false positives cross this threshold, but a few true positives with odds ratios of 1.4 and higher fall slightly below the cut-off significance level. Hence, these SNPs will be reported as false negatives although they have very low $P$ values between $10^{-6}$ and $5 \times 10^{-8}$.

Figure $3 \mathrm{c}$ repeats the same exercise with a sample size of $n=30,000$. This time, all SNPs with an odds ratio of 1.5 or higher are correctly identified. Also, a majority of SNPs with an odds ratio of 1.2 are detected and can be differentiated from ineffective SNPs.

In addition to the effect size (odds ratio) of the effective allele, other factors also influence the power of genetic association studies, such as the chosen type 1 error, the minor allele frequency (MAF), the linkage disequilibrium of the marker, and the true-associated variant. There are also confounding factors such as population structure and geography, misclassification errors, and selection biases 
Fig. $3 P$ values versus odds ratios for three different sample sizes. Panel a $n_{y=1}=100$ and $n_{y=0}=900$, panel $\mathbf{b}$

$n_{y=1}=1,000$ and

$n_{y=0}=9,000$, and panel $\mathbf{c}$

$n_{y=1}=3,000$ and

$n_{y=0}=27,000$. For each panel 550,000 SNPs are simulated, including 30 SNPs with odds ratios greater than 1, i.e. $150 \mathrm{SNPs}$ have a known association with $y=1$. Some SNPs with high odds ratios achieved $P$ values smaller than $10^{-160}$ and are therefore not shown

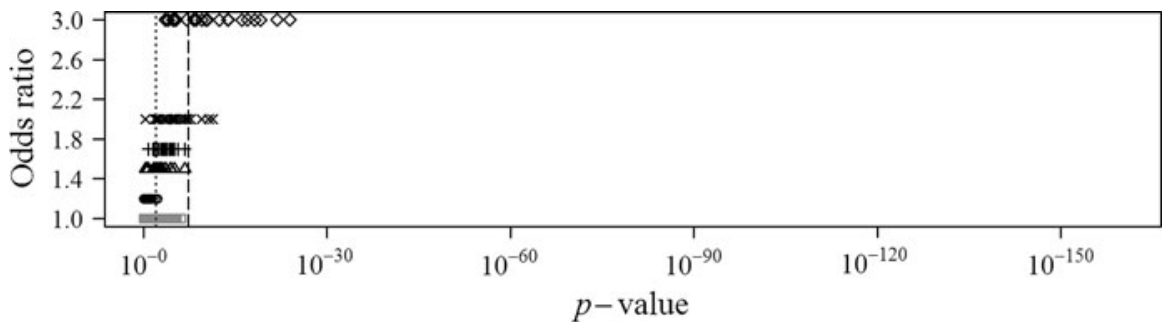

(a)

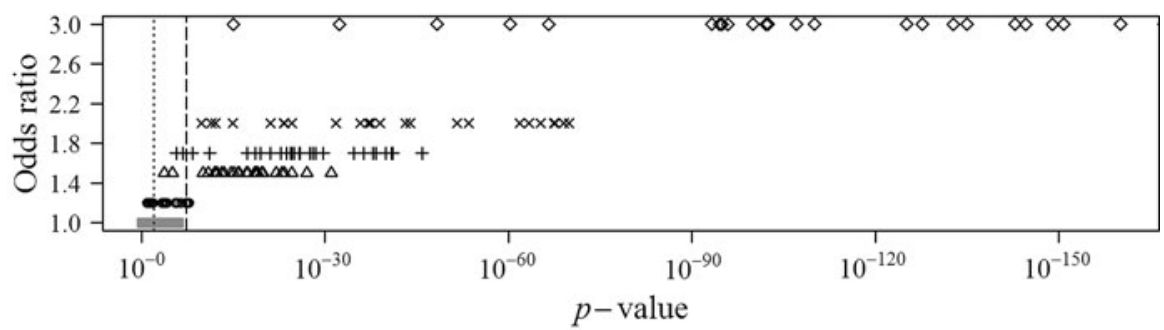

(b)

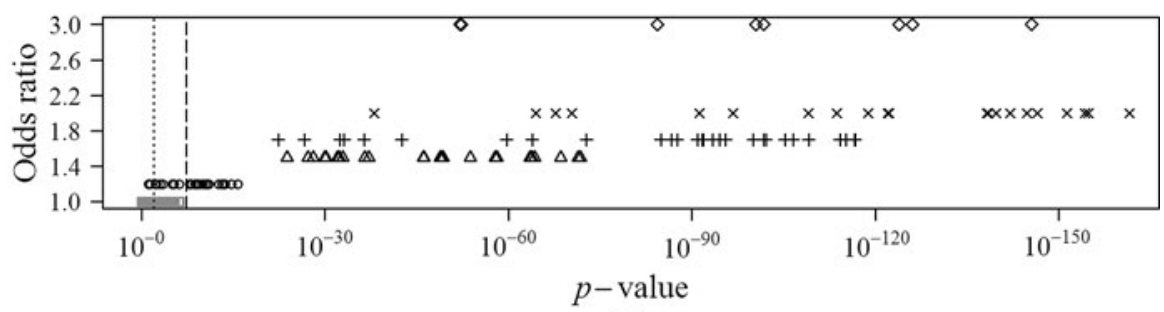

(c)
(Wang et al. 2005). Based on the genetic power calculator by Purcell et al. (2003), Fig. 4 illustrates the joint influence of MAF and odds ratios on the required sample size that is needed to detect true positives in a sample with a $10 \%$ share of individuals who exhibit $y=1$, again closely matching the typical set-up of a GWAS on entrepreneurship. For example, with a MAF of $20 \%$ and an odds ratio of 1.3 , the figure shows that a sample of approximately $n=15,000$ is needed to have an $80 \%$ probability of detecting a true association. It is obvious that the sample size required to detect true positives can easily become enormous if the effective minor allele has a frequency of less than 0.2 and if the odds ratio is smaller than 1.3. Unfortunately, there is no way of ruling out that most or even all true positives lie in this range of parameters, ex ante.

How likely is it that the genetic factors associated with economic behavior such as entrepreneurship will have small odds ratios? Medicine has already discovered many genetic disorders that are complex, multifactorial, or polygenic; disorders likely to be associated with multiple genes in combination with lifestyle and environmental factors. Some examples of such genetically complex diseases identified under GWAS on are listed in Table 4. Frequently, weak effects of single loci are found with odds ratios that are in the range of, or smaller than, 1.2 (e.g. Alzheimer's disease, bipolar disorder, breast cancer, lung cancer, multiple sclerosis, and type 2 diabetes). If these genetically complex diseases are any guideline, we should expect that the SNPs associated with entrepreneurship and other complex behaviors will also have weak effects.

This demonstrates that very large sample sizes are needed to find small effects. Not only are such large genotyped samples very costly to obtain, but most datasets of genotyped cohorts that are currently available are not nearly large enough for this purpose. At this point in time, the best available solution lies in 
Fig. 4 Effects of allele frequency and allelic odds ratio on sample-size requirements. Numbers shown are for a statistical power of $80 \%$ for a chisquare test within a two-bytwo table at a significance level of $P$ value $<5 \times 10^{-8}$ for a sample with $10 \%$ of $y=1$

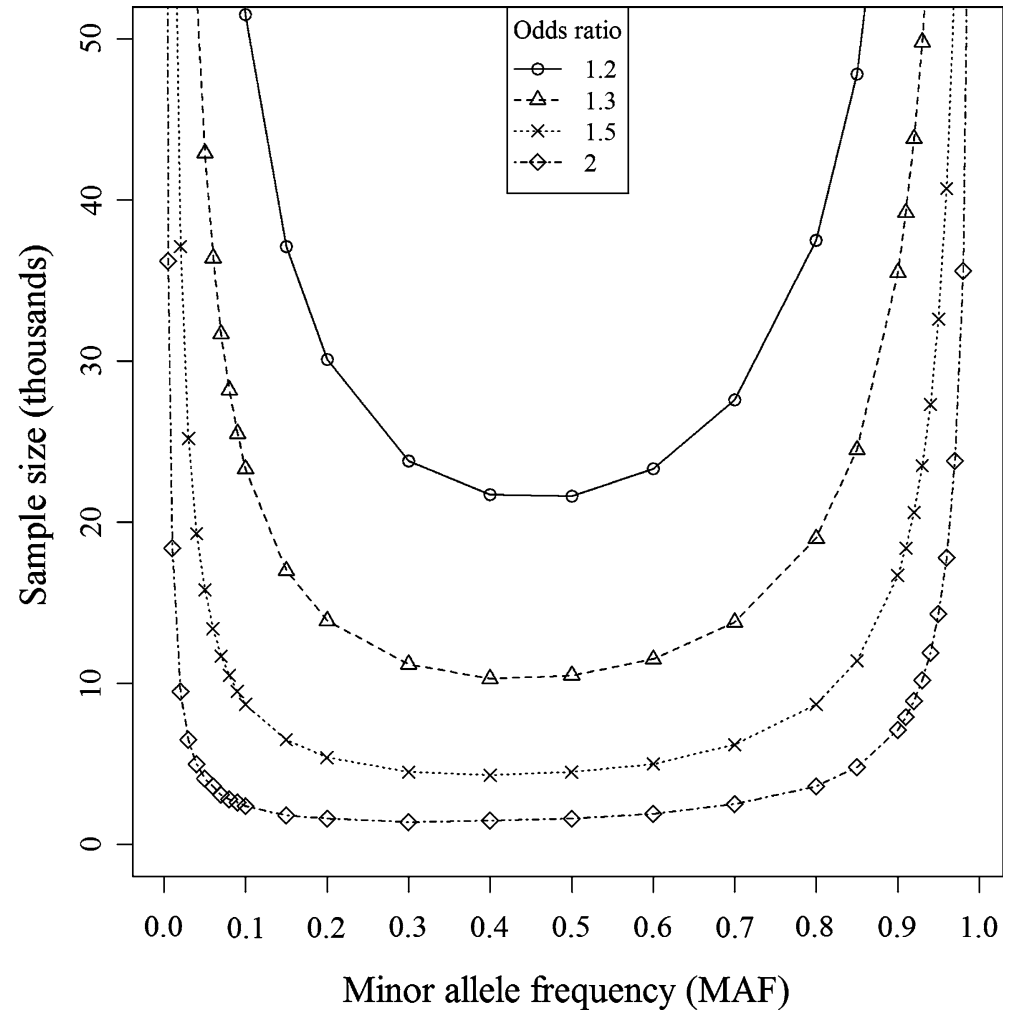

the meta-analysis of several independent cohorts. In this study design, a consortium of different cohorts is formed that includes genotyped individuals and sufficient information on the outcome of interest such as the presence of a disease or an economic outcome like self-employment or educational attainment. Within the consortium, independent GWAS are performed on each sample, following harmonized standards for the phenotype definition, SNP filtering, and model specification. The results of each GWAS are then meta-analyzed using software such as Metal. $^{7}$

Given the typical sample size of genotyped cohorts used in medical research, often more than five large independent cohorts must be included for a metaanalysis to reach sufficient statistical power. This implies that setting up and managing a consortium requires substantial time investments and a long-term commitment to the research project before publishable findings become available. An additional challenge is that any two GWASs will typically use

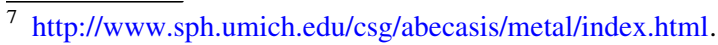

overlapping but non-identical SNP maps due to the variety of genotyping technologies available. Thus, not every SNP is genotyped in every study, but one still wants to obtain a measure of statistical significance for each individual SNP, taking into account all evidence ('direct' and 'indirect') from all studies. The typical strategy in such cases is to impute genotypes for all 'missing' SNPs in all cohorts, and carrying out the analysis as if the imputed data were observed. This is possible because the HapMap project provides independent samples of haplotypes ${ }^{8}$ that can be used as reference to impute missing alleles in a study using software such as MACH (Li and Abecasis 2006) or IMPUTE (Marchini et al. 2007). The resulting imputed samples often have more than 2 million SNPs, which decreases the power of the analysis even further and in principal requires the use of even stricter confidence levels to avoid false positive according to the Bonferroni correction $\left(4 \times 10^{-9}\right.$ if 2 million tests are carried out and a significance level of $1 \%$ is desired for the entire

\footnotetext{
8 A haplotype is the specific combination of alleles at several loci on a single chromosome that are inherited together.
} 
Table 4 Sample of results from GWAS studies on genetically complex traits

\begin{tabular}{|c|c|c|c|c|c|c|c|c|}
\hline Trait/disease & $y=1$ & $y=0$ & $\begin{array}{l}\text { Sample } \\
\text { size }\end{array}$ & $\begin{array}{l}\text { Lowest } \\
\text { overall } \\
\text { odds ratio }^{\mathrm{a}}\end{array}$ & $\begin{array}{l}\text { Associated } \\
P \text { value }\end{array}$ & $\begin{array}{l}\text { Highest } \\
\text { overall } \\
\text { odds ratio }\end{array}$ & $\begin{array}{l}\text { Associated } \\
P \text { value }\end{array}$ & Reference \\
\hline Alzheimer's disease & 5,964 & 10,188 & 16,152 & 1.16 & $10^{-9}$ & 2.53 & $2 \times 10^{-157}$ & Harold et al. (2009) \\
\hline Bipolar disorder & 1,868 & 2,938 & 4,806 & 1.03 & $7 \times 10^{-6}$ & 2.08 & $6 \times 10^{-8}$ & $\begin{array}{l}\text { Wellcome Trust Case } \\
\text { Control Consortium } \\
(2007)\end{array}$ \\
\hline Breast cancer & 27,036 & 25,253 & 52,289 & 1.04 & $9 \times 10^{-6}$ & 1.26 & $2 \times 10^{-76}$ & Easton et al. (2007) \\
\hline Lung cancer & 9,531 & 9,674 & 19,205 & 1.15 & $8 \times 10^{-9}$ & 1.24 & $5 \times 10^{-10}$ & Wang et al. (2008) \\
\hline Multiple sclerosis & 4,839 & 9,336 & 14,175 & 1.10 & $2 \times 10^{-7}$ & 2.75 & $4 \times 10^{-225}$ & De Jager et al. (2009) \\
\hline Type 2 diabetes & 3,836 & 12,562 & 16,398 & 1.15 & $3 \times 10^{-6}$ & 1.20 & $8 \times 10^{-9}$ & $\begin{array}{l}\text { Steinthorsdottir } \\
\text { et al. (2007) }\end{array}$ \\
\hline
\end{tabular}

${ }^{\text {a }}$ Overall odds ratio refers to the odds ratio achieved by combining the discovery and replication samples

family of tests). Nevertheless, there are several degrees of correlation (linkage disequilibrium) between markers resulting in the use of a significance threshold of $5 \times 10^{-8}$ which takes into account the number of independent common variants (tests) in the genome.

Hence, the replication and meta-analysis of several samples in one study is often necessary to identify small genetic effects. In addition to addressing the multiple testing problem, the meta-analysis study design has a secondary effect that may be either desirable or undesirable from the point of view of an economist interested in genetic causes of behavior: meta-analysis has a bias for identifying loci that have a similar association with economic behavior in different environments. This is because the cohorts included in a meta-analysis are unlikely to be collected from identical geographic, economic and cultural settings. For example, to conduct a metaanalysis on entrepreneurship it is necessary to include cohorts from various regions since no single homogenous region is likely to have a sufficient number of genotyped individuals available. In the Gentrepreneur Consortium we are currently running (Van der Loos et al. 2010), cohorts from the Netherlands, the United States, Great Britain, Germany, and Iceland are included. This study design tends to suppress alleles that are effective in only one country, but ineffective in any of the other countries. This is desirable if the research objective is to identify genetic factors that are characteristic of entrepreneurs across different economic and cultural environments. However, if the objective is to identify and to compare different genetic determinants of entrepreneurship in different environments, very large samples in each country will be needed that allow the identification of true positives, with or without the application of metaanalysis. At this point of time, this will only be possible for very few countries, if at all.

One final factor aggravating the need for large samples is that one cannot assume that the economic behavior of men and women are triggered by the same SNPs. For example, in an empirical study on the correlates of nascent entrepreneurship Wagner (2007) demonstrates that men and women cannot be pooled in one sample because the estimated coefficients of the unpooled samples differ significantly from each other, in particular with respect to the effect of fear of failure. Grilo et al. (2007) present similar results using the concept of the entrepreneurial ladder. Arguably, men and women face different demands and constraints when making decisions, whether about education, the formal job market, the amount of time to invest in money earning activities, and whether to choose self-employment or a wage job (Cowling and Taylor 2001; Verheul et al. 2009). If men and women face different environmental circumstances that require different skills and attitudes to cope with to achieve a particular economic outcome, the same genes would not necessarily be linked to this economic outcome. An example is entrepreneurship because both genders may face different motivations and environmental constraints in their occupational choice, which may lead to different genes being 
associated with entrepreneurship for men and women. As a result, separate GWAS should be conducted on entrepreneurship for both genders. However, this requires even larger samples to identify SNPs with relatively small effects.

In summary, the required sample size for a GWAS on an economic outcome of interest can easily get very large ( $>50,000$ observations) if the effective alleles have odds ratios of 1.2 or lower; if the frequency of the effective minor allele is low $(<20 \%)$, if the outcome of interest is rare $(<20 \%$ of the population), and if there is an interaction between genes and the environment that leads to country-, time-, or gender-specific associations. On the other hand, strong genetic effects with odds ratios of 3 or greater can already be detected with sample sizes of around 1,000 observations. However, given previous findings on genetically complex behaviors, it is unlikely that many economic outcomes will be found that can be clearly linked to a limited number of genes with strong effects. Based on our discussion, we expect sample sizes of at least 30,000 observations will be required to identify SNPs associated with economic outcomes such as entrepreneurship.

\section{How to interpret GWAS results}

Given the discussion above, it is obvious that GWAS results below the threshold of genome-wide significance are likely to be false positives. But what does it mean if a particular study does not find SNPs that reach genome-wide significance? Does this mean that genes are not important? Although this is one of the possible causes for not finding genome-wide significance, it is certainly not the only one. Our simulations demonstrate that a plausible alternative explanation is that the study is underpowered: it does not have enough observations to find SNPs with weak effects. In addition, it could be that different genes are associated with an economic outcome in different environments, which will make it difficult to detect the SNPs with meta-analysis using data from different regions or time periods. For example, let us assume that one way genes influence the propensity to become an entrepreneur is via risk preferences. Generally, greater willingness to tolerate risk should increase the probability that an individual will choose self-employment over wage work (Kihlstrom and
Laffont 1979; Cramer et al. 2002). However, the risk of entrepreneurship for the individual may depend on the cultural and economic context. To illustrate, assume that entrepreneurship is less risky in the USA than in Japan because failing with an entrepreneurial business may be more severely punished in Japan than in the USA. While failure may result in severely restricted job offers and lower wages in Japan, it may actually be regarded as positive in the USA, which could lead to better job offers following the entrepreneurial episode of an individual. Consequently, genes influencing risk preferences may be more strongly associated with entrepreneurial behavior in Japan than in the USA. In fact, the relationship may be completely absent or even reversed in the USA, if the above assumptions are true. Hence, a metaanalysis pooling observations from both countries would tend to 'overlook' genes associated with risk preferences although they may be highly relevant in the Japanese context.

Furthermore, there are a number of limitations in current SNP arrays that could be responsible for not finding the true genetic determinants of behavior. For example, rare SNPs (i.e. base pairs that vary in only a very small part of a population) are not covered by current SNP arrays and the most effective SNPs may be found there.

In addition, there are exceptions to the rule that people carry exactly two copies of each SNP, one inherited from each parent (Redon et al. 2006). Instead, there are regions in the genome where people have copy number variants, ranging from zero to 14 copies of a gene. Such copy number variants are not yet recorded in most SNP arrays although they occur frequently throughout the genome and cover hundreds of genes, disease loci, functional elements, and segmental duplications. These copy number variants could not only influence the susceptibility to diseases (Freeman et al. 2006; Estivill and Armengol 2007), but also the tendency to become an entrepreneur or other economic outcomes.

Another way how inherited changes could influence economic behavior is via epigenetics. Epigenetics refers to the fact that changes in phenotype (appearance) or gene expression can be caused by mechanisms other than changes in the underlying DNA sequence. These changes may persist through cell divisions for the remainder of the cell's life and may also be passed on for numerous generations 
without any change in the underlying DNA sequence. An example of epigenetic effects is the process of cell differentiation: a single fertilized egg cell changes into the many cell types including bones, muscles, blood vessels, organs, etc. as it continues to divide. It does so by activating some genes while inhibiting others (Reik 2007). Epigenetic effects occur via several mechanisms, including changes in nutrition. For example, an experiment on agouti mice, which are yellow, fat, and susceptible to life-shortening diseases like cancer and diabetes, found that a change in diet of mother mice could have far-reaching consequences for their offspring (Waterland and Jirtle 2003). In the experiment, a test group of mother mice were fed a diet rich in methyl donors, small chemical clusters that can attach to, and turn off, a gene. Although these mother mice passed on the agouti gene to their offspring, their children were slender and mousy brown instead of yellow and fat. Furthermore, in addition to living longer, the offspring did not display the susceptibility to cancer and diabetes found in the parents.

Epigenetic effects can also be induced after birth and can be long lasting, passing through several generations without changing the underlying DNA sequence. Medical scientists are still coming to understand the many ways that epigenetic changes unfold. However, there is increasing evidence that genes are not necessarily fate and genetic functions can be switched on and off through nutrition or exposure to environmental risk factors. Of course epigenetic effects that cause heritable differences in behavior are not revealed by the GWAS design.

Rare SNPs, copy number variants, and epigenetic effects are just examples illustrating that the GWAS design does not cover all the potential pathways in which traits and economic outcomes can be heritable. In addition, the vast sample sizes required to identify SNPs with small effective could be prohibitively large. Consequently, not finding any genome-wide significant hits in a GWAS does not allow for the conclusion that genes are not relevant for the outcome under investigation.

This is an important insight because it helps reconcile findings from GWAS and from twin studies that appear conflicting at first glance. For example, numerous studies of twins find that intelligence and general cognitive ability are heritable to a significant extent (Deary et al. 2006; Plomin 1999; Plomin and Kosslyn 2001; Plomin and Spinath 2004). Yet, until now GWAS have not been successful at identifying loci associated with IQ scores; even though this is one of the most intensively researched traits in behavioral genetics.

As discussed in Sect. 3, one reason for this discrepancy is that it is very difficult to identify effective SNPs with low odds ratios in GWAS since very large samples are required. However, if intelligence, entrepreneurship and many other human traits and behaviors are genetically complex traits, then it is reasonable to expect that many SNPs with low odds ratios will be found once sufficiently large sample sizes have been gathered. Furthermore, numerous small genetic effects can easily add up in total importance, especially if the effective SNPs interact with each other. This could help to explain the discrepancy between relatively weak effects of SNPs discovered in GWAS and the strong estimated importance of genes often reported in studies of twins. However, it could also be that particular SNPs are only effective in narrowly defined environments. In this case, it is unlikely that even extremely large scale GWAS meta-analyses will discover genomewide significant SNPs although different genes may be important for the behavior of individuals in their particular environment.

Another reason for the discrepancy between the results in twin studies and GWAS are shortcomings in the design of twin studies that may lead to an overestimation of the importance of genes. First, twin studies require the assumption of a shared, identical environment for twins. A violation of this assumption can lead to an overestimation of genetic effects (Rutter 2006). A second potential shortcoming of twin studies is the assumption that $\mathrm{MZ}$ twins are genetically identical. It was recently found that this is not true as even MZ twin pairs often exhibit different copy number variation profiles (Bruder et al. 2008). Not much is known about how these different profiles can influence behavior and if these differences are more pronounced among MZ or DZ twin pairs. Not accounting for such genetic differences among twins introduces a potential bias into the twin study design. Finally, the structural equation models (SEM) used in twin studies only indicate one possible explanation of the underlying correlation matrix. They do not allow one to conclude that the model is true or unique 
because other SEM models may also fit the same data.

Given the methodological difficulties of GWAS and twin studies, it is possible that twin studies tend to give an 'upper bound' for the relevance of genes in explaining an outcome of interest, while GWAS give a 'lower bound', potentially overlooking many important heritable factors. We emphasize here that GWAS is designed to identify common factors, i.e. those with a population frequency of at least $5 \%$. For the identification of rarer genetic risk factors different technology and study designs are necessary. Furthermore, most, if not all, current GWAS analyses are focused on identifying genetic risk factors with an additive effect (rather than dominant or recessive effects), and on identifying individual genetic risk factors (rather than gene-gene and gene-environment interactions). In other words, effects departing from these assumptions are easily missed and require particular attention and sufficiently powered samples.

The essential question is what does it mean if a GWAS finds genome-wide significance for one or several loci. Does this imply genetic determinism together with environmental irrelevance and lack of free will? Luckily, such interpretation is usually not warranted. Firstly, ongoing epigenetic research has identified various mechanisms that affect how genes, the environment, and behavior can interact, thus leading to long-lasting differences in cell functions. Secondly, so far most research on behavioral genetics and on the genetics of diseases does not find a strict determinism between a particular gene and a specific outcome. In most cases, genes are neither a necessary nor sufficient condition for an outcome to occur. Rather, genes influence the probability that an event occurs, often conditional on non-genetic factors such as the exposition to an environmental risk factor or choice (Rutter 2006). For example, there are genes associated with smoking (Caporaso et al. 2009) and with lung cancer (Wang et al. 2008). Not everyone with these genes smokes or gets lung cancer, and many people who smoke and get lung cancer do not have these genes. Yet, having these genes significantly increases the probability of smoking and lung cancer. In particular, a genetic predisposition to lung cancer is likely to be amplified by smoking, while an absence of the exposure to smoke is likely to reduce the risk of lung cancer even for those with the genetic predisposition. Similar interactions between genes, the environment, and free will can be expected for economic outcomes such as entrepreneurship. Hence, if GWAS finds effective alleles for entrepreneurship, this will most probably indicate a genetic predisposition to an outcome that will only materialize in the presence of appropriate environmental conditions and conscious choice. It is then necessary to understand the causal pathway of the genetic effect to draw economically valuable conclusions. Is the genetic effect present in different environments? Is it linked to other well-known characteristics of entrepreneurs such as a low degree of risk aversion or overconfidence? Are there differences in the way genes influence the entrepreneurial propensity of men and women? And how do the biological, psychological and economic mechanisms work that lead to these associations?

From our point of view, the absence of genomewide significant results in GWAS on entrepreneurship does not necessarily contradict results from twin studies that suggest a high importance of heritability. Rather, it most likely means that the available sample sizes are not large enough or that the most important factors cannot be found among common SNPs. Increasing sample size and looking at other places such as rare SNPs, copy number variants and epigenetic effects would be the next step. While the discovery of specific SNPs associated with entrepreneurship would be an important finding, it would not be the end of the quest. The next step would be understanding how the causal pathway from genes to behavior works and how robust these findings are in different environments. Only then could one start drawing conclusions regarding optimal individual behavior and economic policy.

\section{Conclusion: genetics in economics research?}

For economists who believe that a better understanding of economic behavior is an end in itself, the virtues of GWAS and genetics in economic research are evident. Genetics can help us understand the root of individual differences, for example with respect to preferences and productivity values. Also, genetics can help discover new dimensions of individuality that influence economic behavior; those not yet part of established theory. We find this prospect exciting 
and promising enough to justify this time-consuming and risky endeavor using this approach.

But beyond curiosity as a motivation, are there clear, tangible results economists could expect to get out of this approach? Arguably, the history of science teaches us that the social relevance of many discoveries is not readily and rapidly apparent. Also, most discoveries have little if any social relevance and it is difficult to determine ex ante which research agenda is the most promising. Yet, we dare to speculate about some potential benefits of economists looking at genes here.

First, genetic differences across populations may be discovered that will help to explain aggregate economic outcomes. For example, Global Entrepreneurship Monitor data shows that immigrant countries have a higher share of nascent entrepreneurs than other countries (Levie 2007; Ali et al. 2008). One potential explanation, from a genetic point of view, are founder effects (a special case of genetic drift): if a small group from a population splinters off and founds a new population in a geographically distant area, the new population is likely to exhibit different shares of alleles at specific loci in the DNA. In this case, the genetic predisposition of the founders will have very strong and long-lasting effects on the genetic make-up of the new population far into the future that could influence their behavior. ${ }^{9}$ If the spinoff population is very small, it will not be possible to represent all genetic variants found in the original population. Furthermore, the spin-off decision could have genetic determinants. For example, if there are genetic predispositions to low risk aversion and novelty seeking, these genes will tend to be overrepresented in immigrant nations that were initially populated by mavericks and explorers. Consequently, there could be a higher average genetic predisposition to entrepreneurial behavior in such countries, independent from the institutional framework conditions or push effects resulting from social marginalization

\footnotetext{
${ }^{9}$ A well-known example for this effect is the high prevalence of people suffering the Ellis van Creveld syndrome in the North American Amish population, which can be traced back to two members of the new colony started in Pennsylvania in 1744 (Cavalli-Sforza et al. 1996).
}

or isolation. This higher level of (genetically induced) entrepreneurial behavior could then have further repercussions in productivity figures, available job offers, wages, and the ability of the economy to adapt quickly to structural changes.

Second, detailed insights into the genetics of economic behavior and its causal pathways may improve our understanding of the scope and potential boundaries for economic policies. For example, a poor fit between genetic predisposition and occupational choice may result in lower monetary income. In addition, not attaining desired social status can affect life expectancy (Rablen and Oswald 2008) and potentially other non-monetary determinants of utility such as general health. Hence, people may have a genetic predisposition for a particular occupation and there may be a price tag on not finding one's 'occupational destiny'. Insights along these lines may enable more targeted, maybe even personalized support for people during their educational and work life.

Our conclusion is that GWAS is a promising approach to investigate the genetic causes of economic outcomes. However, as with other genetically complex traits, we expect that very large sample sizes will be needed: in the magnitude of several ten thousand observations, which will lead to a high cost for each true positive discovered. Doubtless the financial and administrative resources necessary to gather the necessary data are beyond the means of most economics departments and research institutes. This, and the rapid progress in the fields of genetics, implies that close cooperation between economics and medical departments will be imperative for finding genetic determinants of economic outcomes.

Finally, it is worth emphasizing that genetics is still a young and rapidly developing research field. GWAS are a significant improvement to earlier approaches in genetics; approaches that have already delivered a wealth of invaluable new insights. However, it is unlikely to be the final word. Rapid scientific and technological progress will enable even better and cheaper insights in the human genome in the future. This will lead to more and better data availability and methodological improvements that can also be used for studying economic outcomes of interest, with entrepreneurship being just one prominent example. Hence our belief that economists can and will learn something useful by looking at genes. 
Acknowledgements Comments by Adam Lederer and Jonathan Beauchamp are gratefully acknowledged. For Matthijs van der Loos and Roy Thurik this note has been written in cooperation with the research program SCALES, carried out by EIM and financed by the Dutch Ministry of Economic Affairs.

Open Access This article is distributed under the terms of the Creative Commons Attribution Noncommercial License which permits any noncommercial use, distribution, and reproduction in any medium, provided the original author(s) and source are credited.

\section{References}

Ali, A., Allen, I. E., Brush, C., Bygrave, W. D., De Castro, J., Lange, J., et al. (2008). What entrepreneurs are up to: 2008 National entrepreneurial assessment for the United States of America. Wellesley, MA: Babson College.

Andersson, L., \& Hammarstedt, M. (2010). Intergenerational transmissions in immigrant self-employment: Evidence from three generations. Small Business Economics, 34, 261-276.

Arvey, R. D., Bouchard, T. J., Jr., Segal, N. L., \& Abraham, L. M. (1989). Job satisfaction: Environmental and genetic components. Journal of Applied Psychology, 74, 187-192.

Benz, M., \& Frey, B. S. (2008). Being independent is a great thing: Subjective evaluations of self-employment and hierarchy. Economica, 75, 362-383.

Betsworth, D. G., Bouchard, T. J., Jr., Cooper, C. R., Grotevant, H. D., Hansen, J.-I. C., Scarr, S., et al. (1994). Genetic and environmental influences on vocational interests assessed using adoptive and biological families and twins reared together and apart. Journal of Vocational Behavior, 44, 263-278.

Block, J., \& Koellinger, P. (2009). I can't get no satisfactionNecessity entrepreneurship and procedural utility. Kyklos, 62, 191-209.

Bruder, C. E. G., Piotrowski, A., Gijsbers, A. A. C. J., Andersson, R., Erickson, S., Díaz de Ståhl, T., et al. (2008). Phenotypically concordant and discordant monozygotic twins display different DNA copy-number-variation profiles. American Journal of Human Genetics, 82, 763-771.

Bygrave, W. D., \& Hofer, C. W. (1991). Theorizing about entrepreneurship. Entrepreneurship: Theory and Practice, $16,13-22$.

Camerer, C., \& Lovallo, D. (1999). Overconfidence and excess entry: An experimental approach. American Economic Review, 89, 306-318.

Caporaso, N., Gu, F., Chatterjee, N., Sheng-Chih, J., Yu, K., Yeager, M., et al. (2009). Genome-wide and candidate gene association study of cigarette smoking behaviors. PLoS ONE, 4, 1-10.

Cavalli-Sforza, L. L., Menozzi, P., \& Piazza, A. (1996). The history and geography of human genes (p. 413). Princeton, N.J.: Princeton University Press.

Cesarini, D., Dawes, C. T., Johannesson, M., Lichtenstein, P., \& Wallace, B. (2009a). Genetic variation in preferences for giving and risk taking. Quarterly Journal of Economics, 124, 809-842.

Cesarini, D., Lichtenstein, P., Johannesson, M., \& Wallace, B. (2009b). Heritability of overconfidence. Journal of the European Economic Association, 7, 617-627.

Collins, F. S., Morgan, M., \& Patrinos, A. (2003). The human genome project: Lessons from large-scale biology. Science, 300, 286-290.

Colombier, N., \& Masclet, D. (2008). Intergenerational correlation in self employment: Some further evidence from French ECHP data. Small Business Economics, 30, 423437.

Comings, D. E., Rosenthal, R. J., Lesieur, H. R., Rugle, L. J., Muhleman, D., Chiu, C., et al. (1996). A study of the dopamine D2 receptor gene in pathological gambling. Pharmacogenetics, 6, 223-234.

Cowling, M., \& Taylor, M. (2001). Entrepreneurial women and men: Two different species? Small Business Economics, 16, 167-175.

Cramer, J. S., Hartog, J., Jonker, N., \& van Praag, C. M. (2002). Low risk aversion encourages the choice for entrepreneurship: An empirical test of a truism. Journal of Economic Behavior \& Organization, 48, 29-36.

Crisp, D. J., Beaumont, A. R., Flowerdew, M. W., \& Vardy, A. (1978). The Hardy-Weinberg test-A correction. Marine Biology, 46, 181-183.

De Jager, P. L., Jia, X., Wang, J., de Bakker, P. I. W., Ottoboni, L., Aggarwal, N. T., et al. (2009). Meta-analysis of genome scans and replication identify CD6, IRF8 and TNFRSF1A as new multiple sclerosis susceptibility loci. Nature Genetics, 41, 776-782.

Deary, I. J., Spinath, F. M., \& Bates, T. C. (2006). Genetics of intelligence. European Journal of Human Genetics, 14, 690-700.

Dunn, T., \& Holtz-Eakin, D. (2000). Financial capital, human capital, and the transition to self-employment: Evidence from intergenerational links. Journal of Labor Economics, 18, 282-305.

Easton, D. F., Pooley, K. A., Dunning, A. M., Pharoah, P. D. P., Thompson, D., Ballinger, D. G., et al. (2007). Genome-wide association study identifies novel breast cancer susceptibility loci. Nature, 447, 1087-1093.

Ebstein, R. P., Novick, O., Umansky, R., Priel, B., Osher, Y., Blaine, D., et al. (1996). Dopamine D4 receptor (D4DR) exon III polymorphism associated with the human personality trait of novelty seeking. Nature Genetics, 12, 7880.

Estivill, X., \& Armengol, L. (2007). Copy number variants and common disorders: Filling the gaps and exploring complexity in genome-wide association studies. PLoS Genetics, 3, 1787-1799.

Evans, D. S., \& Leighton, L. S. (1989). Some empirical aspects of entrepreneurship. American Economic Review, 79, 519-535.

Freeman, J. L., Perry, G. H., Feuk, L., Redon, R., McCarroll, S. A., Altshuler, D. M., et al. (2006). Copy number variation: New insights in genome diversity. Genome Research, 16, 949-961.

Freytag, A., \& Thurik, A. R. (2007). Entrepreneurship and its determinants in a cross-country setting. Journal of Evolutionary Economics, 17, 117-131. 
Grilo, I., \& Thurik, R. (2008). Determinants of entrepreneurial engagement levels in Europe and the US. Industrial and Corporate Change, 17, 1113-1145.

Grilo, I., Thurik, R., Verheul, I., \& van der Zwan, P. (2007). Climbing the entrepreneurial ladder: The role of gender (ERIM Report Series in Management ERS-2007-098ORG). Rotterdam, The Netherlands: Erasmus Research Institute of Management.

Groenen, P. J. F., Hofman, A., Koellinger, P., van der Loos, M. J. H. M., Rivadeneira, F., van Rooij, F., et al. (2008). Genome-wide association for loci influencing entrepreneurial behavior: The Rotterdam Study. Behavior Genetics, 38, 628-629.

Guedj, M., Nuel, G., \& Prum, B. (2008). A note on allelic tests in case-control association studies. Annals of Human Genetics, 72, 407-409.

Hardy, G. H. (1908). Mendelian proportions in a mixed population. Science, 28, 49-50.

Harold, D., Abraham, R., Hollingworth, P., Sims, R., Gerrish, A., Hamshere, M. L., et al. (2009). Genome-wide association study identifies variants at CLU and PICALM associated with Alzheimer's disease. Nature Genetics, 41, 1088-1093.

Hartley, J. E. (1996). Retrospectives: The origins of the representative agent. Journal of Economic Perspectives, 10, 169-177.

Hindorff, L. A., Sethupathy, P., Junkins, H. A., Ramos, E. M., Mehta, J. P., Collins, F. S., et al. (2009). Potential etiologic and functional implications of genome-wide association loci for human diseases and traits. Proceedings of the National Academy of Sciences USA, 106, 9362-9367.

Hirschhorn, J. N., Lohmueller, K., Byrne, E., \& Hirschhorn, K. (2002). A comprehensive review of genetic association studies. Genetics in Medicine, 4, 45-61.

Hofman, A., Breteler, M. M. B., van Duijn, C. M., Janssen, H. L. A., Krestin, G. P., Kuipers, E. J., et al. (2009). The Rotterdam Study: 2010 objectives and design update. European Journal of Epidemiology, 24, 553-572.

Hoggart, C. J., Clark, T. G., De Iorio, M., Whittaker, J. C., \& Balding, D. J. (2008). Genome-wide significance for dense SNP and resequencing data. Genetic Epidemiology, $32,179-185$.

Israel, S., Lerer, E., Shalev, I., Uzefovsky, F., Reibold, M., Bachner-Melman, R., et al. (2008). Molecular genetic studies of the arginine vasopressin 1a receptor (AVPR1a) and the oxytocin receptor (OXTR) in human behaviour: From autism to altruism with some notes in between. Progress in Brain Research, 170, 435-449.

Iyigun, M. F., \& Owen, A. L. (1998). Risk, entrepreneurship, and human capital accumulation. American Economic Review, 88, 454-457.

Jovanovic, B. (1994). Firm formation with heterogeneous management and labor skills. Small Business Economics, 6, 185-191.

Keller, L. M., Bouchard, T. J., Jr., Arvey, R. D., Segal, N. L., \& Dawes, R. V. (1992). Work values: Genetic and environmental influences. Journal of Applied Psychology, 77, 79-88.

Kihlstrom, R. E., \& Laffont, J.-J. (1979). A general equilibrium entrepreneurial theory of the firm based on risk aversion. Journal of Political Economy, 87, 719-748.
Kirman, A. P. (1992). Whom or what does the representative individual represent? Journal of Economic Perspectives, 6, 117-136.

Kluger, A. N., Siegfried, Z., \& Ebstein, R. P. (2002). A meta-analysis of the association between DRD4 polymorphism and novelty seeking. Molecular Psychiatry, 7, $712-717$.

Knafo, A., Israel, S., Darvasi, A., Bachner-Melman, R., Uzefovsky, F., Cohen, L., et al. (2008). Individual differences in allocation of funds in the dictator game associated with length of the arginine vasopressin 1a receptor RS3 promoter region and correlation between RS3 length and hippocampal mRNA. Genes, Brain and Behavior, 7, 266-275.

Knight, F. H. (1921). Risk, uncertainty, and profit. Boston, MA: Houghton Mifflin Company.

Koellinger, P., Minniti, M., \& Schade, C. (2007). "I think I can, I think, I can": Overconfidence and entrepreneurial behaviour. Journal of Economic Psychology, 28, 502527.

Laussel, D., \& Le Breton, M. (1995). A general equilibrium theory of firm formation based on individual unobservable skills. European Economic Review, 39, 1303-1319.

Lazear, E. P. (2004). Balanced skills and entrepreneurship. American Economic Review, 94, 208-211.

Lazear, E. P. (2005). Entrepreneurship. Journal of Labor Economics, 23, 649-680.

Lentz, B. F., \& Laband, D. N. (1990). Entrepreneurial success and occupational inheritance among proprietors. Canadian Journal of Economics, 23, 563-579.

Levie, J. (2007). Immigration, in-migration, ethnicity and entrepreneurship in the United Kingdom. Small Business Economics, 28, 143-169.

Li, Y., \& Abecasis, G. R. (2006). Mach 1.0: Rapid haplotype reconstruction and missing genotype inference. American Journal of Human Genetics, S79, 2290.

Marchini, J., Howie, B., Myers, S., McVean, G., \& Donnelly, P. (2007). A new multipoint method for genome-wide association studies by imputation of genotypes. Nature Genetics, 39, 906-913.

McCarthy, M. I., Abecasis, G. R., Cardon, L. R., Goldstein, D. B., Little, J., Ioannidis, J. P. A., et al. (2008). Genomewide association studies for complex traits: consensus, uncertainty and challenges. Nature Review Genetics, 9, 356-369.

Miller, P., Mulvey, C., \& Martin, N. (2001). Genetic and environmental contributions to educational attainment in Australia. Economics of Education Review, 20, 211-224.

Nicolaou, N., \& Shane, S. (2009). Can genetic factors influence the likelihood of engaging in entrepreneurial activity? Journal of Business Venturing, 24, 1-22.

Nicolaou, N., Shane, S., Cherkas, L., Hunkin, J., \& Spector, T. D. (2008a). Is the tendency to engage in entrepreneurship genetic? Management Science, 54, 167-179.

Nicolaou, N., Shane, S., Cherkas, L., \& Spector, T. D. (2008b). The influence of sensation seeking in the heritability of entrepreneurship. Strategic Entrepreneurship Journal, 2, $7-21$.

Pérez de Castro, I., Ibáñez, A., Torres, P., Sáiz-Ruiz, J., \& Fernández-Piqueras, J. (1997). Genetic association study between pathological gambling and a functional DNA 
polymorphism at the $\mathrm{D} 4$ receptor gene. Pharmacogenetics, 7, 345-348.

Plomin, R. (1999). Genetics and general cognitive ability. Nature, 402(Supp), C25-C29.

Plomin, R., \& Kosslyn, S. M. (2001). Genes, brain and cognition. Nature Neuroscience, 4, 1153-1155.

Plomin, R., \& Spinath, F. M. (2004). Intelligence: Genetics, genes, and genomics. Journal of Personality and Social Psychology, 86, 112-129.

Psaty, B. M., O’Donnell, C. J., Gudnason, V., Lunetta, K. L., Folsom, A. R., Rotter, J. I., et al. (2009). Cohorts for Heart and Aging Research in Genomic Epidemiology (CHARGE) Consortium: Design of prospective metaanalyses of genome-wide association studies from five cohorts. Circulation: Cardiovascular Genetics, 2, 73-80.

Purcell, S., Cherny, S. S., \& Sham, P. C. (2003). Genetic power calculator: Design of linkage and association genetic mapping studies of complex traits. Bioinformatics, 19, 149-150.

Purcell, S., Neale, B., Todd-Brown, K., Thomas, L., Ferreira, M. A. R., Bender, D., et al. (2007). PLINK: A tool set for whole-genome association and population-based linkage analysis. American Journal of Human Genetics, 81, 559575.

Rablen, M. D., \& Oswald, A. J. (2008). Mortality and immortality: The Nobel Prize as an experiment into the effect of status upon longevity. Journal of Health Economics, 27, 1462-1471.

Redon, R., Ishikawa, S., Fitch, K. R., Feuk, L., Perry, G. H., Andrews, T. D., et al. (2006). Global variation in copy number in the human genome. Nature, 444, 444-454.

Reik, W. (2007). Stability and flexibility of epigenetic gene regulation in mammalian development. Nature, 447, 425432.

Roessler, C., \& Koellinger, P. (2009). Firm formation with complementarities: The role of the entrepreneur (TI Discussion Paper 09-003/3). Rotterdam, The Netherlands: Tinbergen Institute.

Rutter, M. (2006). Genes and behavior-Nature-nurture interplay explained (pp. 41-44). Oxford, UK: Blackwell Publishing.

Sasieni, P. D. (1997). From genotypes to genes: Doubling the sample size. Biometrics, 53, 1253-1261.

Steinthorsdottir, V., Thorleifsson, G., Reynisdottir, I., Benediktsson, R., Jonsdottir, T., Walters, G. B., et al. (2007). A variant in CDKAL1 influences insulin response and risk of type 2 diabetes. Nature Genetics, 39, 770-775.
Sturges, H. A. (1926). The choice of a class interval. Journal of the American Statistical Association, 21, 65-66.

The International HapMap Consortium. (2005). A haplotype map of the human genome. Nature, 437, 1299-1320.

Thurik, A. R., Carree, M. A., Van Stel, A., \& Audretsch, D. B. (2008). Does self-employment reduce unemployment? Journal of Business Venturing, 23, 673-686.

Van der Loos, M. J. H. M., Koellinger, P. D., Groenen, P. J. F., \& Thurik, A. R. (2010). Genome-wide association studies and the genetics of entrepreneurship. European Journal of Epidemiology, 25, 1-3.

Van der Zwan, P., Thurik, R., \& Grilo, I. (2010). The entrepreneurial ladder and its determinants. Applied Economics, forthcoming.

Verheul, I., Carree, M., \& Thurik, R. (2009). Allocation and productivity of time in new ventures of female and male entrepreneurs. Small Business Economics, 33, 273-291.

Verheul, I., Uhlaner, L., \& Thurik, R. (2005). Business accomplishments, gender and entrepreneurial self-image. Journal of Business Venturing, 20, 483-518.

Wagner, J. (2007). What a difference a Y makes-Female and male nascent entrepreneurs in Germany. Small Business Economics, 28, 1-21.

Wang, W. Y. S., Barratt, B. J., Clayton, D. G., \& Todd, J. A. (2005). Genome-wide association studies: Theoretical and practical concerns. Nature Reviews Genetics, 6, 109-118.

Wang, Y., Broderick, P., Webb, E., Wu, X., Vijayakrishnan, J., Matakidou, A., et al. (2008). Common 5p15.33 and 6 p21.33 variants influence lung cancer risk. Nature Genetics, 40, 1407-1409.

Waterland, R. A., \& Jirtle, R. L. (2003). Transposable elements: Targets for early nutritional effects on epigenetic gene regulation. Molecular and Cellular Biology, 23, $5293-5300$

Weinberg, W. (1908). Über den Nachweis der Vererbung beim Menschen. Jahreshefte des Vereins für vaterländische Naturkunde in Württemberg, 64, 368-382.

Wellcome Trust Case Control Consortium. (2007). Genomewide association study of 14,000 cases of seven common diseases and 3,000 shared controls. Nature, 447, 661-678.

Wennekers, S., \& Thurik, R. (1999). Linking entrepreneurship and economic growth. Small Business Economics, 13, 27-55.

Zhang, Z., Zyphur, M. J., Narayanan, J., Arvey, R. D., Chaturvedi, S., Avolio, B. J., et al. (2009). The genetic basis of entrepreneurship: Effects of gender and personality. Organizational Behavior and Human Decision Processes, 110, 93-107. 